it falls in a straight line to the bottom, where it spreads out in a dense layer. When the apparatus is again set working, the purest acid is drawn from the npper layers. There is, consequently, some advantage in using a tall bottle for $\mathrm{A}$.

4. It may be put together in a form which has all the advantages possessed by the Schanche generator (see this JoukNAL, Dec. 1894 .) Making the glass tube $\mathrm{R}$, long enough to reach to the top of $B$, and to curve a little downward, so that the acid may drop on the top of the solid charge and trickle through it. A drainage-tube with stop-cock must be inserted into the cork to carry off the used-up acid from the space 5 . The inverted bottle for $B$, possesses this advantage over the calcium chloride tube or chimney; viz., that owing to the position of the mouth of the gas exit tube $F$, solid particles are not so likely to be shot into it when the acid is vigorously attacking the solid charge.

5. The pressure can be regulated at will by placing $A$ at different heights, and this pressure may, at any monent, be reinforced by blowing into $A$, and the reinforcement held by closing $M$ by means of a rubber tube and pinch-cock.

\title{
SOME OF THE PROPERTIES OF CALCIUM CARBIDE.
}

BY F. P. VENABLE ANU THOMAS CLAKKE

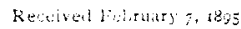

THE calcium carbide used was prepared by the Willson Aluminum Company. In this preparation, lime is mixed with some form of carbon, as coal-tar; the mass is then heated, with stirring, until a thorough mixture is obtained. The proportions are so arranged that the mass becones dry and hard on cooling. This mass, in lumps, is then placed in the electric furnace. In a very short time after the turning on of the current, the process is complete. The molten mass can be run out of the crucible or it may be removed after cooling. On examination, it is easy to see that there is more or less of carbon unchanged, or rather converted into the graphitic variety by the intense heat. Along with this are to be seen crystalline masses, lustrous and dark brownish black it color.

These are quite hard, and break with a crystalline fracture. Several efforts at effecting a separation from the graphitic carbon 
were unsuccessful. The luster is slowly lost on exposure to air, more rapidly if the air be filled with moisture. The whole will finally crumble down into a gray powder with particles of black graphite interspersed through it. The carbide can be kept for a year or two if placed in a tightly stoppered bottle and is quite easily preserved if a little coal-oil is placed in the vessel containing it.

By far the most interesting property of this carbide is its decomposition when brought in contact with water. The metallic carbides seem to be distinguished by the ease with which they exchange their carbon for the oxygen of water or for the radicals of various acids, the carbon combining with the hydrogen to form various hydrocarbons. Several authors have reported that the decomposition of this particular hydrocarbon caused the formation of acetylene. Experiments were carried out by us proving this fact, some time before there were any publications concerning it in the chemical journals, but we were not at liberty to publish anything concerning it at that time. If the gas, as evolved, is passed through a set of absorption flasks containing ammoniacal copper solution it will be entirely absorbed, not a bubble passing through, out of one or two liters of the gas. Thus it seems to be pure acetylene. The amount of gas yielded by any one sample will be affected to some extent by the amount of graphitic carbon present. Hence different lots will vary somewhat. The average is about $200 \mathrm{cc}$. to the gram of carbide.

If the gas be ignited as it is evolved it gives a smoky flame; if it be considerably diluted, as one part of gas to from six to ten of air, a flame of great brilliancy and intensity is gotten. A company has been formed to introduce this as an illuminant upon the market. The cheapness of the materials used and the ease with which the gas can be formed ought to make it a valuable and useful addition to our illuminants. If too large a proportion of air be admixed a very violent explosion can be brought about by igniting it. In some cases we have noticed the flame rapidly travelling backwards along a rubber tube towards the gasometer in which the gas was stored. One explosion taught us that care was necessary in handling the mixture.

Several analyses were attempted of the carbicle, but for obvious 
reasons failed to give very satisfactory results. In the first place there was uncombined carbon present, also a small portion of a tarry matter which could be detected by heating to high temperatures, and lastly, the specimens worked upon were severai months old and in spite of careful keeping, had been slightly acted upon by the air and so contained uncombined line or calcium carbonate. Moissan gives $\mathrm{C}$. $\mathrm{C}$ as the formula calculated from his analyses. This wotld agree well with the decomposition by water; $\mathrm{C}_{2} \mathrm{Ca}+\mathrm{H}_{2} \mathrm{O}=\mathrm{C}_{2} \mathrm{H}_{2}+\mathrm{CaO}$.

Action of Hydrogen upon the Carbidc.-Dry hydrogen has no action upon this carbide in the cold. Several small pieces of the carbide were placed in a piece of combustion tubing, drawn out at one end to a point suitable for testing the flame. Dry inydrogen was then passed over it and as soon as the air was expelled the hydrogen was ignited at the jet and a lamp placed under the tube so as to heat the carbide. In a little while the colorless fiame became luminous and remained so a short time. A brownish tarry matter condensed in the cooler parts of the tube. The mass of the carbide assumed a dull gray tint and a very thin white sublimate collected at a short distance from where the tube was heated. The ignition was carried on for five hours. The driving off of this tarry matter seemed to be the only action. The substance on removal from the tube, was still hard. On exposure to the air, it disintegrated, and, if thrown into water, it was decomposed, showing the same behavior as the original carbide.

Action of Air and of $0 x y g c n$. - Sone fresh pieces of the carbide were placed in the tube and heated while dry air was passed over them. A luminous flame was gotten as before and the same tarry matter was driven off and then there seened to be no further action. Tests showed the carbide apparently unchanged at the end of prolonged heating.

Oxygen was then passed over some of the carbide which was being moderately ignited. No change was observed after two hours' heating. If the temperature was very high, such as that gotten in a cumbustion furnace, the carbicle glowed brightly, as if burning, and a nearly white powder was obtained. The combustion was imperfect, however, unless the tube was very hot and the ignition prolonged. This refers not merely to the gra- 
phitic carbon mixed with the carbide but to the carbide itself. In several experiments the substance withdrawn from the tube, after heating some hours in oxygen, decomposed violently in water. It may be added, as was to be expected, that carbon dioxide had no appreciable action upon the carbide.

Action of Hydrochloric Acid.-Hydrochloric acid had no action upon this substance in the cold. When passed over the heated substance it caused it to swell up and assume a dirty gray appearance. A small amount of a liquid, apparently water, collected in the cooler portions of the tube and parts of the carbide fused down in glassy globules and masses. These were soluble in water and were easily shown to be calcium chloride. White fumes were evolved some of which settled as a white solid upon the sides of the tube.

Action of Chlorine and Bromine.-When chlorine was passed over fresh carbide in the cold no action was observed. If even a moderate heat was applied, however, the lumps of carbide glowed very brightly, swelled, and fused together. A slight yellowish white sublimate was found in the tube. The fused mass was calcium carbide.

Bromine mixed with air was then passed over the fresh carbide. In the cold no action was observed. On heating, the carbide became red and the smaller pieces glowed. The lumps fused together and bubbles were observed on the surface as if some gas was escaping from the mass. Some condensed matter was found afterwards in the tube, and, on cooling, a peculiar odor was noticed different from that of bromine. The fused mass dissolved readily in water and gave the tests for calcium bromide. Of course in this and the previous experiment the black specks of graphitic carbon were found unchanged. It was easy to distinguish them from the carbide. A few pieces of the carbide were dropped into strong, freshly prepared, chlorine water. There was a very violent disengagement of gas but it was not ignited as reported by Moissan. The gas was inflammable and burnt very much like acetylene. The odor was, however, peculiar. The same experiment was tried several times with a concentrated solution of bromine in water. The action again was very violent but there was no spontaneous ignition of the gas. 
Little difference could be detected between this and the action of the chlorine water.

Action of Acids. - A piece of the carbide was placed in concentrated pure sulphuric acid. A few small bubbles came off but the action seemed slight. On heating, the action was greatly increased and continued after the removal of the flame. A gas was given off which burned with a luminous flame.

A mixture of sulphuric acid and potassium jichromate acted most violently upon the carbide. There seened to be a very vigorous oxidation, and several attempts at igniting the gas given off resulted in failure. There could have been very líttle, if any, acetylene present $i n$ it.

Strong nitric acid attacked the carbicle with the formation of brown-red fumes. The gas evolved could be ignited and burned with a smoky flame.

Glacial acetic acid decomposed the carbide slowly in the cold. It may be added that no change was observed on adding a piece of the carbide to some boiling sulphur. On allowing the mass to cool the carbide was regained in its original condition. Action of Alkalics. - A few grams of sodium hydroxide were melted in a nickel dish and a piece of the carbide was added. There was riolent action, a gas being given off which burned with a luminous flame and which was taken to be acetylene.

A small amount of sodium dioxide was also melted in a nickel dish. When the carbicie was added to this it was rapidly attacked, the action being about the same as in the experiment just mentioned. An inflammable gas was evolved.

In conclusion, we would give due credit to Mr. W. R. Kenan, who carefully verified some of the experiments here recorded.

vivikstry of NoRTI CAROIANA. I'ebruary, I893.

\section{NOTE ON THE DETERMINATION OF ZINC.}

BY P. W. ShIMER. EAston, PA. Received January 24, 2895 .

THE manganese in many zinc ores is a disturbing element in the accurate determination of metallic zinc. As is well known the usual separation of zinc from manganese is made by precipitating the zinc as sulphide in a solution which is strongly 